\title{
Limites e possibilidades para a configuração do reconhecimento em redes sociotécnicas ${ }^{1}$
}

\section{Angela Pintor dos Reis}

\section{Resumo}

Este estudo discute como os atributos de redes sociotécnicas podem colaborar para a emergência de formas mediáticas do reconhecimento e também podem colocar em xeque a possibilidade dessa experiência intersubjetiva. A reflexão se articula a partir das seguintes bases: a epistemologia do reconhecimento desenvolvida por Honneth; os princípios e as funcionalidades do Facebook, assumidos como corpus de referência; e 0 procedimento adotado e discutido por Deleuze, de subtração de elementos de um objeto para a liberação de seus sentidos não dominantes. A relação entre essas bases levou ao deslocamento conceitual do reconhecimento para sua admissão no contexto de redes sociotécnicas.

\section{Palavras-Chave}

Redes sociotécnicas. Reconhecimento. Sociabilidade.

Angela Pintor dos Reis I angelapintor@terra.com.br Doutora em Comunicação e Semiótica pela Pontifícia Universidade Católica de São Paulo - PUC-SP, Brasil. Desenvolve pesquisa de Pós-Doutorado no Departamento de Cinema, Rádio e Televisão da Escola de Comunicações e Artes da Universidade de São Paulo. - USP, Brasil. Atua no Centro Interdisciplinar de Pesquisas em Comunicação e Cibercultura (CENCIB/PUC-SP). Professora no Centro Universitário Senac, Brasil.

\author{
Cultivamos o hábito de viver \\ antes de adquirir o de pensar. \\ Nesta corrida que todo dia nos precipita \\ um pouco mais em direção à morte, \\ o corpo mantém uma dianteira irrecuperável.
}

Albert Camus

\section{Introdução}

Honneth é um dos principais autores na

teoria social entre aqueles que se dedicam ao estudo do reconhecimento como experiência intersubjetiva própria de contextos democráticos e, consequentemente, de lutas sociais. Uma de suas obras mais relevantes dedicadas ao tema conceitua o reconhecimento, sucintamente falando, como ação moral praticada entre indivíduos ou grupos sociais com vistas à aceitação do outro como portador de direitos e fonte de pretensões legítimas (HONNETH, 2003). 0 autor aponta a existência de três principais esferas nas quais se processam, nas condições apontadas, lutas intersubjetivas por reconhecimento: a afetiva, a jurídica e a social (HONNETH, 2003, p. 155-211).

Em outro trabalho, Honneth (2011, p. 165-181) desenvolveu uma epistemologia do reconhecimento baseada no princípio de visibilidade social e 
ancorada no conceito de respeito na filosofia moral de Kant. A visibilidade social de que trata Honneth corresponde à experiência de alguém ser tanto percebido quanto valorizado por outrem. Para ilustrar seu ponto de vista, 0 autor recorre à novela Invisible man (ELLISON, 2001) como exemplo que consubstancia a diferença, fundamental, entre alguém ser visto (ou percebido por outrem em seu campo visual) e ser considerado como destino de atenção e consideração. A novela tem como cenário a sociedade norte-americana da década de 1950 e, neste contexto, as lutas provocadas pela segregação social e violência racial contra a população negra nos Estados Unidos. 0 personagem principal que motiva o título da obra está configurado como um negro que abre a narrativa declarando perceber a si próprio como um homem invisível. A razão disso é sua consciência de ser socialmente ignorado, situação que lhe causa sofrimento e 0 faz duvidar de sua própria existência. A miséria social do personagem é gestada, como ele mesmo explica, no modo como está construído o olhar das pessoas; elas olham para tudo ao redor dele, mas não direta e fixamente para ele, de maneira a não simbolizar a consideração de sua presença (ELLISON, 2001, p. 3-4; HONNETH, 2011, p. 165-166).

Com esse exemplo, Honneth destaca a diferença entre alguém ser percebido, porque o corpo comparece no campo visual de outrem, e ser apreciado ou reconhecido como fonte de pretensões legítimas, no sentido de 0 indivíduo (ou grupo social) ser admitido como válido em suas demandas. Somente nesta segunda situação estariam dadas as condições para o reconhecimento processar-se e, para isso, a experiência intersubjetiva deveria, fundamentalmente, ser orientada pelo respeito, conforme conceituado por Kant. Para este filósofo, o respeito é um sentimento que se produz por meio da razão, separado, portanto, de outros sentimentos provenientes das inclinações sensíveis do sujeito (KANT, 2011, p. 33); o respeito corresponde à consciência da subordinação da vontade à lei como mandamento necessário em si, e dessa obediência resulta a representação de um valor que causa dano ao amor-próprio do sujeito (KANT, 2011, p. 33). ${ }^{2}$ Honneth (2011, p. 176)

Esta é uma versão modificada do artigo apresentado no I Seminário Internacional de Pesquisas em Midiatização e Processos Sociais, realizado na Universidade do Vale do Rio dos Sinos, no período de 12 a 15 de dezembro de 2016.

Essa definição enseja uma discussão que merece atenção, porém, não pode ser desenvolvida aqui. Na filosofia moral de Kant, 0 respeito é arrimo da moralidade como trabalho da razão pura prática - que se dedica aos princípios a priori, isto é, independentes da experiência - e está inscrito no âmbito da vontade pura, sinônima do bem supremo e ilimitadamente bom (KANT, 2011, p. 21). Ao interpretar a filosofia moral de Kant, Höffe (2005, p. 194) alerta para o fato de que "[...] 0 critério (metaético) da moralidade [...], o ser-bom ilimitado só se cumpre lá onde o correto moral não é realizado a partir de nenhuma outra razão que pelo fato de ele ser moralmente correto, lá, portanto, onde o próprio dever é querido e é como tal cumprido." Logo, em Kant, a moralidade não pode ser observada na conduta dos indivíduos (HÖFFE, 2005, p. 194). Em termos sucintos, a vinculação da epistemologia do reconhecimento ao conceito de respeito em Kant evidencia uma conjuntura articulada [1] pelo empenhamento da concepção do reconhecimento com um pensamento que admite a impossibilidade de simbolização da moralidade e, por consequência, do reconhecimento; e/ou [2] pela interpretação do respeito em Kant em sentido não literal quanto ao seu significado e contexto de origem, mas por associação de ideias ou por empréstimo conceitual, para o estabelecimento de um móbil que qualifique o reconhecimento como ação moral. 
interpretou essa definição como a necessidade de o sujeito renunciar a uma posição egocêntrica em uma relação, colocando-se mediante a alteridade de maneira descentrada. Nessas condições seria possível a incorporação do espírito do respeito para o consequente reconhecimento do outro como fonte de pretensões legítimas.

Nessa epistemologia, a visibilidade social não equivale ou não contempla, de maneira específica, a visibilidade em sua forma sociotécnica, isto é, elaborada no concurso entre corpo, subjetividade e tecnologia de comunicação. Trata-se, antes, da concepção de um valor, atribuído ou incorporado por indivíduos ou grupos sociais, que deve ser simbolizado na função de princípio norteador das relações intersubjetivas em contextos democráticos. Nesse caso, a visibilidade social é condição de indivíduos ou grupos sociais e sua extensão ocorre na simbolização do ato de admitir 0 outro válido em suas pretensões como prova da veridicidade dessa ação. Em outras palavras, a própria simbolização precisa ser valorizada na sociabilidade para a concretização do reconhecimento.

Se visibilidade social e respeito constituem a circunstância sem a qual o reconhecimento não sobrevive concretamente, no sentido de ser verificável por meio de sua simbolização e, assim, parecer verossímil, as mediações que problematizam ainda mais a veridicidade da simbolização do valor do outro (quando se acredita que o simbolizado é capaz de guardar correspondência exata em relação a uma suposta univocidade da intenção de valorizar o outro) põem em dúvida a possibilidade de 0 reconhecimento ser experiência intersubjetiva possível em determinadas conjunturas. Esse problema abrange relações processadas em redes sociotécnicas, nas quais restam reunidos, confrontados, conciliados e baralhados estímulos gestados no encontro entre subjetividade e propriedades tecnológicas.

Essas redes são concebidas aqui com base no argumento de Castoriadis (1982, p. 301-306) de que a técnica é social, no sentido de que é criada pelo imaginário instituinte do socialhistórico, em seu trabalho de engendramento constante de formas e de suas correspondentes significações. As redes sociotécnicas - sua concepção e operação - são, portanto, expressões da atividade do imaginário social, que confere existência a objetos, práticas e valores, e institui relações de significação entre esses elementos, todos atinentes à vigência social do corpo/da subjetividade, no processo de criação de um tecido de sentido para determinada sociedade. A partir dessa perspectiva, as redes sociotécnicas expressam-se tanto na forma de redes baseadas em serviços tecnológicos para a sociabilidade (a exemplo do Facebook) quanto, simultaneamente, como arquiteturas socioculturais de época com as quais sujeito e outro se relacionam na inquietação de construir sentido para sua existência que não é outra senão social. [Em última instância, 0 termo "rede sociotécnica" ou até mesmo a palavra 
"sociotécnica" apresenta dupla redundância (se é possível quantificar o desnecessário), por excesso de significação produzido pela linguagem, em sua obsessão por designar fenômenos e todas as formas do outro].

Pretender encontrar condições para a dimanação do reconhecimento nas relações elaboradas nesse ambiente de sociabilidade exige admitir, de partida e no mínimo, a dificuldade - se não a impossibilidade - de se alcançar a verdade dessa experiência intersubjetiva, materializada na suposta certeza sobre a vigência de seu fundamento, a saber, o respeito, tal qual definido por Kant e incorporado por Honneth à sua epistemologia. Esse embaraço decorre das seguintes razões:

[1] porque o respeito como sentimento ou ação da razão se produz no concurso de forças tais como as projeções de valores de época, a imaginação, a moral construída desde a socialização primária, as operações da percepção, as necessidades e as contingências com as quais sujeito e alteridade estão empenhados para que seja possível a vida social. Nesse caso, o respeito como valor não se situa mais no âmbito da razão pura, prática teorizada por Kant, mas comparece como valoração do outro na empiria e volatilidade da sociabilidade cotidiana; e

[2] porque é necessário ao menos aventar a possibilidade de a visibilidade social, na função de requisito primordial para a concretização do reconhecimento, também se processar na sociabilidade mediatizada das redes sociotécnicas, uma vez que a vida social é, na atualidade, articulada pela relação entre corpo-mente, media (de massa e interativos) e tecnologias de informação e comunicação, configurando um continuum entre sociabilidade presencial e em redes sociotécnicas.

Essas considerações abrem a questão relativa às possíveis condições para a emergência de formas mediáticas do reconhecimento na extensão da vida cotidiana, especificamente na sociabilidade em redes sociotécnicas. 0 pensamento de base considera que 0 reconhecimento existe como potência, isto é, está disponível nas relações intersubjetivas que perfazem a vida social e se aglutinam em experiências moduladas por conjunturas e contextos - em relações entre parceiros sexuais, na família, no trabalho, na militância política, nas instituições de ensino e religiosas, nas relações de amizade etc. Nestes contextos, as relações intersubjetivas estão disseminadas tanto em ambientes presenciais quanto em redes sociotécnicas como dimensões conexas e formadoras de uma cultura mediática. 0 reconhecimento comparece nesse cenário como experiência constituinte do sujeito, na medida em que este se estatui com a colaboração inextricável do outro e do ambiente sociocultural, o que confere inevitabilidade a essa experiência intersubjetiva também na sociabilidade mediatizada. 
A discussão que se põe a partir desse ponto de vista está alicerçada nos procedimentos especificados adiante.

[1] Por conveniência didática e necessidade de assentamento da reflexão em uma perspectiva que considerasse preceitos concretos de redes sociotécnicas, constituiu-se um corpus de referência com princípios e funcionalidades do Facebook no Brasil, um dos serviços tecnológicos para redes de sociabilidade mais utilizados no País (BRASIL, 2014). A opção por esse corpus decorre da conjugação do interesse conceitual do presente estudo com a impraticabilidade de se extrair princípios a partir da empiria e da variabilidade das redes sociotécnicas. A intenção, portanto, não é apontar o modo prático de o reconhecimento ocorrer ou não em uma rede sociotécnica específica, mas refletir sobre condições, favoráveis ou não, à emergência de formas de reconhecimento em contexto de sociabilidade mediatizada e, portanto, diverso e distante daquele em que essa experiência intersubjetiva foi originalmente pensada e conceituada.

[2] A reflexão orienta-se pela lógica da operação de subtração-constituição à qual Deleuze (2010, p. 25-64) se refere ao discutir o método de trabalho do dramaturgo, ator e cineasta italiano Carmelo Bene. ${ }^{3}$ Segundo Deleuze (2010, p. 29-33), Bene extrai elementos estáveis de poder de uma peça para liberar seu devir e fazê-la percorrer caminhos imprevistos, para além de uma perspectiva normalizada e dominante. Com base nesse pensamento e na metodologia que lhe subjaz, optou-se pela eliminação do elemento fundante e de poder do reconhecimento, a saber, o respeito, para que fosse possível considerar a emergência de condições que dessem passagem a formas mediáticas dessa experiência intersubjetiva, resultantes de um plano sociotécnico de imanência da sociabilidade.

\section{Condições para a emergência do reconhecimento em redes sociotécnicas}

Ao sistematizarem a história dos sites de redes sociotécnicas, Boyd e Ellison (2007) arrolaram uma série de funcionalidades que caracterizam esses espaços de sociabilidade como propositalmente disponíveis para promover a visibilidade do sujeito para uma rede de contatos ou "amigos". Essa rede pode combinar relações nascidas e cultivadas no mundo da sociabilidade presencial com relações originárias de contatos iniciados e mantidos exclusivamente no ambiente digital. Segundo as autoras (2007, p. 211), embora os sites de redes sociotécnicas tenham tipicidades não necessariamente coincidentes e nomeiem as propriedades de suas interfaces cada um à 
sua maneira, há características comuns entre eles no que diz respeito às possibilidades oferecidas aos seus participantes, a saber: [1] construir um perfil público ou semipúblico; [2] articular uma lista de usuários com os quais mantêm contatos; e [3] ver e cruzar sua lista de contatos para multiplicá-los. Essas características confirmam-se no Facebook, em termos operacionais e institucionais.

0 Facebook é uma empresa de capital aberto que oferece serviços para redes sociotécnicas. No primeiro semestre de 2017 , sua receita total atingiu US\$17,353 bilhões, valor 46,8\% superior ao registrado no mesmo período de 2016, e dos quais US $\$ 17,021$ bilhões provieram de veiculação de publicidade (FACEB00K, 2017a). No mesmo período, 0 lucro líquido alcançou US \$ 6,959 bilhões, com aumento de $73 \%$ sobre os primeiros seis meses de 2016 (FACEB00K, 2017a).

0 êxito da empresa é fruto do empenhamento administrativo-tecnológico com uma missão: "[...] dar às pessoas o poder de compartilhar e fazer o mundo mais aberto e conectado. As pessoas usam o Facebook para ficar conectadas com amigos e com a família, para descobrir o que está acontecendo no mundo, e para compartilhar e expressar o que for importante para elas." ${ }^{4}$ (FACEB00K, 2016b, tradução nossa). Em síntese, o Facebook tem como missão e negócio a própria sociabilidade que se torna possível na medida em que há suporte tecnológico. Para que 0 empreendimento progrida no tempo de maneira consistente, é necessário que os usuários incorporem atributos do serviço, abrangidos pelo trinômio formado por funcionalidades tecnológicas, desenvolvidas para otimizar resultados das conexões entre indivíduos e/ ou entre estes e organizações (entre as quais estão anunciantes); regras dispostas no termo de serviço e na política de dados; e princípios da empresa. Estes últimos instituem, majoritariamente, deveres para os usuários, e parte deles está estritamente relacionada à sociabilidade nas formas de promoção das conexões e de institucionalização de condições para que os indivíduos e organizações "materializem seu aparecimento" em termos mediáticos. A explicitação desses deveres pode ser observada adiante, em cinco dos dez princípios do Facebook. 
Quadro 1: Princípios do Facebook

\begin{tabular}{|c|c|c|}
\hline $\begin{array}{c}\text { Liberdade para compartilhar } \\
\text { e se conectar }\end{array}$ & $\begin{array}{c}\text { As pessoas devem ter a liberdade de compartilhar as informações } \\
\text { que desejarem, de qualquer maneira e em qualquer formato, e têm } \\
\text { o direito de se conectar a qualquer um - qualquer pessoa, organização } \\
\text { ou serviço - desde que ambos estejam de acordo com a conexão. }\end{array}$ \\
\hline Fluxo livre de informações & $\begin{array}{c}\text { As pessoas devem ter a liberdade de acessar todas as informações } \\
\text { disponibilizadas a elas por outras pessoas. Além disso, as } \\
\text { pessoas devem ter as ferramentas práticas para facilitar, agilizar } \\
\text { e otimizar o compartilhamento e acesso a essas informações. }\end{array}$ \\
\hline Valor social & $\begin{array}{c}\text { As pessoas devem ter a liberdade de construir confiança e reputação } \\
\text { por meio de sua identidade e suas conexões, e de não serem removidos } \\
\text { do serviço do Facebook por outras razões além das descritas } \\
\text { na Declaração de Direitos e Responsabilidades do Facebook. }\end{array}$ \\
\hline Serviço fundamental & $\begin{array}{c}\text { As pessoas devem usar o Facebook para estabelecer sua } \\
\text { presença, conectar-se com outros e compartilhar informações. } \\
\text { Todas as pessoas têm o direito de usar o serviço do Facebook } \\
\text { independentemente de seu nível de participação ou contribuição. }\end{array}$ \\
\hline Um mundo & $\begin{array}{c}\text { o serviço do Facebook deve ultrapassar barreiras geográficas } \\
\text { e nacionais e ser disponibilizado a todas as pessoas do mundo. }\end{array}$ \\
\hline
\end{tabular}

Fonte: Facebook (2016c)

Esses princípios se efetivam para os usuários em funcionalidades fomentadoras da sociabilidade tais como "Encontrar amigos", "Solicitações de amizade", "Solicitações de mensagem" e possibilidades de "curtir", "comentar" e "compartilhar" conteúdos. A conjugação dos princípios do Facebook com essas funcionalidades se sumariza na máxima do dever de liberdade.

Este qualifica as conexões entre usuários e, por meio destas, supostamente lastreia a construção de "confiança e reputação" como efeitos do exercício da identidade. Esse mesmo dever de liberdade está implícito nas seguintes determinações: [1] a indispensabilidade do
Facebook para a concretização da "presença" dos indivíduos em conjuntura sociotécnica - similar ao aparecimento de corpo-subjetividade em forma mediática -, subordinando a existência do sujeito à sua exposição e visibilidade sociotécnica; e [2] a permutabilidade entre a "presença" mediática do indivíduo e o projeto do Facebook de ser articulador da vida social em condições espaço-temporais para além dos limites tradicionais; isto é, se o Facebook se pretende indispensável para que a "presença" dos indivíduos se faça em ambiente sociotécnico, e se 0 serviço da empresa ambiciona ser onipresente para a sociabilidade no mundo, a 
aparição mediática dos usuários, para além de fronteiras territoriais e culturais, acompanha a materialização das intenções do Facebook.

No contexto de sociabilidade originário da relação entre subjetividade e capital, como é 0 caso em discussão, dever de liberdade guarda estreita vizinhança com 0 axioma do pensamento liberal, expresso no ideal de liberdade assimilado à condição negativa do sujeito quanto à sua dependência e abertura a outrem. Segundo Petit (2013, p. 617), essa liberdade correspondente à condição de alguém "[...] ser livre da ingerência do outro na busca de atividades que se é capaz, em uma dada cultura, de exercer sem a ajuda do outro." Tal maneira de ser livre pressupõe desimpedimento absoluto "[...] para pensar 0 que se quer, de dizer o que se pensa, de ir aonde se quer, de se associar com quem quer que esteja disposto a fazê-lo, e assim por diante no que se refere a todas as liberdades tradicionais" (PETIT, 2013, p.617). Isso significa, em termos ideais e práticos, desembaraço entre sujeito e outro, considerado fonte não de pretensões legítimas, mas de demandas que, em geral, constrangem ou, na melhor hipótese, exigem alguma restrição ou comedimento na expressão desimpedida de corpo-subjetividade.

Esse ideal de liberdade se condensa nas conexões entre usuários, nas formas de mobilidade e reciclagem das relações, que tanto favorecem quanto problematizam o reconhecimento como experiência intersubjetiva nesse ambiente de sociabilidade. Quanto mais aparelhado estiver 0 corpo-subjetividade para se conectar com outrem, e quanto mais livre estiver para decidir buscar, manter, rejeitar ou ignorar uma conexão - o que equivale a simbolizar a aceitação ou o rechaço do outro -, mais admissível será a concretização de experiências intersubjetivas, entre as quais se incluem o reconhecimento. No entanto, a lógica da mobilidade e reciclagem das conexões igualmente colabora para a impossibilidade do reconhecimento ao desobrigar a relação entre sujeito e outro, uma vez que pressupõe, de partida e como regra, a mutabilidade das conexões na função de recurso disponível para a não conservação das relações. Vale dizer que sujeito e outro, quando estabelecem conexão nessa rede sociotécnica (o Facebook), interagem, também, sem que isso seja explícito ou visível, com um conjunto formado por funcionalidades sociotécnicas, princípios e ideal de liberdade, no qual está embutido, como regra, o desembaraço mútuo.

0 imperativo da mobilidade-reciclagem que rege as conexões situa essa forma de sociabilidade na lógica do dispêndio incondicional, fenômeno constituído, segundo Bataille (2013, p. 19-40), por atividades improdutivas de uma sociedade, que fazem sentido pela perda excessiva de recursos de toda ordem que provocam. 0 giro contínuo e livre de conexões constrói um ambiente superabundante em contatos entre subjetividades e, concomitantemente, alimenta a saturação da sociabilidade - seu excesso, extravasamento, 
redundância e desperdício. De certo modo, essa prodigalidade potencializa a ocorrência de conexões e a visibilidade sociotécnica como condições para o reconhecimento se converter em ato nas relações intersubjetivas. Porém, de outro ponto de vista, pode cooperar para o ocultamento do outro e para a indiferença em relação a ele, motivados pela saturação do campo perceptivo.

0 dever de liberdade no contexto em questão encerra ainda um paradoxo. No sentido de obrigação para com a lei, o dever constitui condições, expressas em normas instituídas pelo Facebook (termos do serviço, política de uso de dados e princípios), nas quais estão circunscritas as ações do sujeito (sem que ele, necessariamente, se dê conta disso). Essas normas cumprem dupla função: metaforicamente, equivalem à lei para a sociabilidade processada nesse ambiente sociotécnico, e operam como espelho da subjetividade elaborada na cultura mediática. Em outras palavras, o dever para com a lei, configurada na relação entre normas e funcionalidades tecnológicas promotoras da sociabilidade, comparece como obrigação do sujeito para vivenciar o que lhe é próprio: a imaginação, o desejo, a sociabilidade e a expressividade (por meio de linguagem verbal e imagens) como mandamentos. Estas forças são emuladas pela tecnologia de comunicação na forma de funcionalidades sociotécnicas e oferecidas como serviço com o qual interagem a imaginação (de si e do outro), o desejo de sociabilidade e a vocação da subjetividade à expressividade e à simbolização.
Outros três fatores se unem a essa configuração sociotécnica, problematizando e favorecendo condições para experiências de reconhecimento em ambientes como o Facebook. Um desses fatores é o processamento da sociabilidade em regime 24/7 (24 horas por sete dias da semana), concebido por Crary (2014) como esquema de operação de corpo-subjetividade no capitalismo tecnológico, do qual o Facebook é parte; seus princípios, sua missão e seus resultados atestam isso. 0 regime 24/7 converteu-se em imperativo sociocultural que se torna possível com a "alucinação da presença" (CRARY, 2014, p. 39), forjada na relação entre dispositivos tecnológicos e corpo-subjetividade, para que seja possível a elaboração de respostas às demandas ininterruptas gestadas nas relações de trabalho, no consumo, no entretenimento e na sociabilidade. A "alucinação da presença" se traduz em reprodução contínua e sem descanso de expressões verbais e imagéticas de corposubjetividade em suporte tecnológico. 0 segundo fator é a economia da atenção provocada pela emergência do poder do software (BUCHER, 2012a) na sociabilidade processada em redes sociotécnicas e, em especial, no Facebook. 0 que está em questão é a colaboração dos algoritmos - regras para captura, processamento e distribuição de dados em ambientes tecnológicos de alta complexidade - para a modulação da sociabilidade. Conforme Napoli (2014), esses objetos tecnológicos participam das relações intersubjetivas interpretando preferências e recomendações de conteúdos entre usuários, e 
retroalimentando-os com conteúdo classificado como valorizado. Ao cumprirem essa tarefa, os algoritmos modelam a atenção (BUCHER, 2012b) e contribuem para a conversão da sociabilidade em negócio. 0 terceiro fator está na função da imagem tecnológica na catalisação da sociabilidade no Facebook. Como afirma Flusser (2010, p. 16-17), juntamente com a subjetividade, as imagens e os objetos (tecnológicos) constituem circunstâncias, abstratas e imaginadas, nas quais se elaboram as experiências intersubjetivas. Nessas condições, a imagem como "superfície imaginada" (FLUSSER, 2010, p. 15) é lugar, expressão e destino de processamento do desejo do sujeito de ser reconhecido pelo desejo do outro.

0 dever de liberdade, acompanhado dos objetos que 0 constituem - as conexões e o enlace que estas favorecem entre subjetividade e funcionalidades sociotécnicas -, produzem condições para a emergência de formas de um reconhecimento de caráter liberal. A especialidade e a motivação dessas formas de experiência intersubjetiva não se sustentam no espírito moral do respeito, mas no livre fluxo de conexões, do qual a visibilidade sociotécnica é parte indispensável. Esse ambiente perfaz uma conjuntura frágil, no que se refere à sua capacidade de viabilizar uma prova da verdade do reconhecimento, na medida em que oferece recursos que incentivam a criação de perfis falsos, protegem a mentira e tornam praticável a liberdade negativa nos termos explicados por Petit (2013, p. 617). Entretanto, ao mesmo tempo em que se afasta a possibilidade de considerar factível o reconhecimento na sociabilidade em discussão, persiste a necessidade de pensar condições para essa experiência em redes sociotécnicas. A razão disso é que esse ambiente é espaço privilegiado de relações intersubjetivas nas quais vigem expectativas por reconhecimento, incentivadas pela existência e vocação dessas redes. 0 próprio nome "Facebook" simboliza um regime de puro oferecimento de corpo-subjetividade ao outro, inscrito em lógica liberal-mediática.

Nessa circunstância, conceber condições possíveis para o reconhecimento em ambiente inóspito a ele, quando consideradas as exigências da epistemologia aqui adotada, implica buscar novos contornos para um modo de relação percebida como constituinte de fenômenos sociomediáticos. Um caminho para esse trabalho interpretativo se condensa no procedimento de subtração do elemento invariante de um objeto para que este se desloque e se abra a outras significações. Essa operação foi discutida por Deleuze (2010, p. 2564) em reflexão sobre 0 trabalho do dramaturgo, ator e cineasta italiano Carmelo Bene. De maneira sinônima à discussão de Deleuze (2010, p. 41-42) sobre o que resta de um objeto quando dele são retirados elementos de poder, coloca-se aqui em questão o que permanece do reconhecimento, para o contexto das redes sociotécnicas, quando dessa experiência é extraído seu elemento de poder, isto é, o respeito na forma de moralidade, que institucionaliza e normaliza o conceito, prevendo ordem à experiência a ele associada. Excluído 
0 respeito como seu elemento constituinte, 0 reconhecimento se libera do crivo da moralidade e de sua exigência para com uma verdade do sujeito, para ser entendido no campo da visibilidade sociotécnica, engendrada no manancial de conexões e no extravasamento de manifestações de corpo-subjetividade.

Esse modo de ser da sociabilidade, à maneira de um liame construído por conexões (ao acaso ou previstas) entre subjetividades, funcionalidades sociotécnicas e normas do ambiente tecnológico, precipita-se em duas frentes de ação: [1] em persistência das conexões, que se conservam em operação ao infinito, e, assim, mantêm a atividade contínua das redes sociotécnicas em ambientes como o Facebook; e [2] em visibilidade sociotécnica como atributo do modo de ser em conexão com outrem. Na correlação entre essas duas frentes, há trabalho das relações intersubjetivas para permanecerem em devir, movimento no qual se inscrevem o outro, as funcionalidades sociotécnicas das redes e, consequentemente, o reconhecimento como possibilidade. Em outras palavras, 0 devir das relações intersubjetivas persevera nas conexões e nas funcionalidades sociotécnicas das redes, e ambas engendram seu sentido no fenômeno da visibilidade sociotécnica. Esta condição de base das redes sociotécnicas é o fluido da liberdade negativa, no qual se elaboram as relações nessas redes. Independentemente do julgamento que se possa fazer dessa configuração, trata-se de um modo de expressão da lógica da vida, conforme concebida por

Spinoza e Deleuze.

Em Spinoza (2015, p. 237, grifo do autor), vida é a "[...] força pela qual as coisas perseveram em seu ser [...]", definição que, segundo Agamben (2000, p. 188), está ligada ao pensamento de Deleuze (1994, p. 8) na medida em que este define vida como "[...] plano de imanência do desejo". Agamben (2000, p. 189) explica a equivalência entre as duas lógicas e, especificamente, a relação entre vida, imanência e desejo, a partir do significado dos termos gregos trepho e trephein ("nutrir, fazer crescer, coagular"), conforme exposto adiante:

Deixar que um ser alcance o estado a que tende,
deixar-se ser: se é este o significado original de
trepho, então a potência que constitui a vida em
sentido primordial (o nutrir a si) coincide com 0
desejo de conservar o próprio ser que define a
potência da vida como imanência absoluta em
Espinosa e Deleuze (AGAMBEN, 2000, p. 189,
grifo do autor).

A coincidência entre vida e desejo de conservar 0 próprio ser é cingida por Deleuze (2002, p. 103110) com a interpretação do termo conatus em Spinoza (2013, p. 175), traduzido pela potência ou pelo esforço por meio do qual algo persevera em seu ser para preservar-se em seu modo de existência. Segundo Deleuze,

[...] 0 conatus define 0 direito do modo existente. Tudo aquilo que eu sou determinado a fazer para perseverar na existência (destruir 0 que convém, 0 que me é nocivo, conservar 0 que 
me é útil ou convém) por afecções dadas (idéias de objetos), sob afetos determinados (alegria e tristeza, amor e ódio...), tudo isso é meu direito por natureza. Este direito é rigorosamente idêntico à minha potência e é independente de toda ordem de fins, de toda consideração de deveres, visto que o conatus é fundamento primeiro, primum movens, causa eficiente e não final (2002, p. 107-108, grifos do autor).

Deleuze continua sua interpretação afirmando que 0 direito do modo existente não é contrário às lutas e às manifestações de ódio, significando que esse direito incorpora desde a beneficência mais construtiva à malignidade mais destrutiva. Esse direito, do qual é indissociável o modo existente, realiza-se no corpo. Este, com suas afecções e seus afetos - suas subjetivações -, independentemente de quais sejam essas e esses, tende a perseverar constituindo um modo existente que se diferencia e se realiza em singularidade e em ato (DELEUZE, 2002, p. 108). A diversidade de modos existentes e de seu êxito está nas condições em que 0 ato se efetiva, nas quais 0 modo existente procurará usar todos os recursos de que dispõe para prosseguir existindo no tempo, conforme explica Deleuze (2002, p. 108):

Podemos conceber um modo existente que se esforça por perseverar na existência, segundo o seu direito de natureza, ao acaso de seus encontros com os outros modos, ao capricho das afecções e dos afetos que o determinam do exterior: esforça-se então por aumentar a sua potência de agir, ou seja, por experimentar paixões alegres, mesmo que seja destruindo o que 0 ameaça [...]. Não só estas alegrias da destruição estão envenenadas pela tristeza e pelo ódio de que procedem [...], mas o acaso dos encontros faz com que corramos sem cessar 0 risco de encontrar algo mais potente do que nós que nos destruirá [...] e, mesmo nos casos mais favoráveis, encontremos os outros modos sob aspectos discordantes e hostis [...]. Eis por que 0 esforço para perseverar, aumentar a potência de agir, experimentar paixões alegres, elevar ao máximo o poder de ser afetado, por mais que sempre se efetue, só se logra na medida em que o homem se esforça por organizar seus encontros: isto é, entre os outros modos, se esforça por encontrar aqueles que convêm com a sua natureza e se compõe com ele, e por encontrá-los sob os mesmos aspectos em que se convêm e compõem. Ora, é este o esforço da Cidade, e, de uma maneira ainda mais profunda, o da Razão: tal esforço conduz o homem não só a aumentar a sua potência de agir, o que ainda é do domínio da paixão, mas igualmente a entrar na posse formal dessa potência e a experimentar alegrias ativas que decorram das idéias adequadas que a Razão forma.

Se 0 modo de perseverar na existência se esforça por constituir relações de identidade, não importa se animadas por paixões alegres ou pelo ódio, que se aglutinam constituindo formações tais como a cidade ou a razão, o modo de perseverar na existência provoca, igualmente, a sociabilidade e, por derivação, a formação de redes sociotécnicas como manifestações em ato da vida no plano de imanência (DELEUZE, 1992, p. 51-79).

Essas reflexões são uma tela interpretativa através da qual as redes sociotécnicas aparecem como formações autogeradas pela coagulação de modos de perseverar em ato. Os modos existentes nesse contexto se esforçam para aumentar sua potência de agir, nutrindo-se com afeções e afetos gerados nas 
relações intersubjetivas dadas nas conexões, tanto ao acaso quanto organizadas. As fontes de sustento desses modos existentes e das próprias redes são as conexões, a visibilidade sociotécnica - configurada no encontro de esforços para perseverar, incorporados por sujeito e outrem - e o reconhecimento na função de alimento disponível para a nutrição e conservação dos modos existentes; essa experiência intersubjetiva se insere no exercício do conatus, um direito do modo existente idêntico à sua potência de existir em ato (DELEUZE, 2002, p. 107). Por essa via, o reconhecimento se transforma em acolhimento da imanência do modo existente, isto é, de seu direito de existir devindo.

\section{Considerações finais}

Este enfoque, aberto com a supressão do eixo moral do reconhecimento, requalifica tanto essa experiência intersubjetiva quanto as próprias redes sociotécnicas, permitindo que ambas sejam compreendidas nos limites da teoria da potência, desenvolvida na relação entre os pensamentos de Deleuze e de Spinoza, em contraste com a abordagem sustentada em uma teoria dos deveres. Isso não quer dizer que essas redes e o reconhecimento estejam livres da perspectiva da moralidade, assim como também não estão isentos de uma interpretação liberal. A partir dos pensamentos de Deleuze e Spinoza sobre o conatus e a vida, a moralidade e a lógica liberal também podem ser consideradas modos existentes na forma de atributos incorporados na relação entre sujeito e outrem, que se precipitam em ato na sociabilidade e na experiência intersubjetiva em questão. Esses modos existentes, em alguma medida e de certo modo, vigem na subjetividade, sem que sejam, sempre e necessariamente, tematizados nas relações em redes sociotécnicas e assumidos como motivação para possíveis atos de reconhecimento.

A lógica dessas redes, ancorada no trinômio constituído por conexões, visibilidade sociotécnica e funcionalidades tecnológicas, pode ser um dos elementos provocadores da variação contínua de formas não convencionais do reconhecimento na vida social. Essas novas formas jorram da incorporação e apropriação livre de condições sociotécnicas, extravasando a configuração canônica do reconhecimento, colocando-a para fora de seu conceito tradicional. Formas em devir do reconhecimento podem não se reportar mais à sua epistemologia de origem, estando livres para novos conceitos que as tipifiquem. E esses novos conceitos serão continuamente tensionados pelo transbordamento da vida da sociabilidade e por sua modificação contínua.

\section{Referências}

ABREU, Ovídio de. 0 procedimento da imanência em Deleuze. Alceu, Rio de Janeiro, v. 5, n.9, p. 87-104, jul./dez. 2004. Disponível em: < http://revistaalceu.com.puc-rio.br/ media/alceu_n9_abreu.pdf $>$. Acesso em: 9 ago. 2016. 
AGAMBEN, Giorgio. A imanência absoluta. In: ALLIEZ, Eric (Org.). Gilles Deleuze: uma vida filosófica. São Paulo: Ed. 34, 2000.

BATAILLE, Georges. A parte maldita, precedida de "A noção de dispêndio". Belo Horizonte: Autêntica: 2013.

BOYD, Danah; ELISSON, Nicole. Social network sites: definition, history and scholarship. Journal of Computer-Mediated Communication, [s. I.], v. 13, n. 1, Oct. 2007. Disponível em: < http://onlinelibrary. wiley.com/doi/10.1111/j.1083-6101.2007.00393.x/full>. Acesso em: 14 out. 2015.

BRASIL. Presidência da República. Secretaria de Comunicação Social. Pesquisa Brasileira de Mídia 2015: hábitos de consumo de mídia pela população brasileira. Brasília: Secom, 2014. Disponível em: $<$ http://www.secom.gov.br/atuacao/pesquisa/lista-depesquisas-quantitativas-e-qualitativas-de-contratosatuais/pesquisa-brasileira-de-midia-pbm-2015.pdf > . Acesso em: 5 mar. 2016.

BUCHER, Taina. A technicity of attention: how software 'makes sense'. Culture Machine, [s. l.], v. 13, $2012 a$. Disponivel em: < http://www.culturemachine.net/index. php/cm/issue/view/24> . Acesso em: 17 out. 2015. . Want to be on the top? Algorithmic power and the threat os invisibility on Facebook. New Media and Society, Los Angeles; London, v. 14, n. 7, Nov. 2012b. Disponível em: < http://nms.sagepub. com/content/14/7/1164.full.pdf +html> . Acesso em: 17 out. 2015.

CAMUS, Albert. 0 mito de Sísifo. Rio de Janeiro: Record, 2014.

CASTORIADIS, Cornelius. A instituição imaginária da sociedade. Rio de Janeiro: Paz e Terra, 1982.

CRARY, Jonathan. Capitalismo tardio e os fins do sono. São Paulo: Cosac Naify, 2014.

DELEUZE, Gilles. 0 que é filosofia? Rio de Janeiro: Ed. $34,1992$.
Desejo e prazer. Magazine Littéraire. Paris, n. 325, out. 1994, p. 57-65. Traduzido por Espaço Michel Foucault. Disponível em: < http://michelfoucault.weebly.com/uploads/1/3/2/1/13213792/art06. pdf > . Acesso em: 9 ago. 2016.

Espinosa: filosofia prática. São Paulo:

Escuta, 2002.

Sobre teatro: um manifesto de menos; 0 esgotado. Rio de Janeiro: Zahar, 2010.

ELLISON, Ralph. Invisible man. London: Penguin Books, 2001.

FLUSSER, Vilém. 0 universo das imagens técnicas: elogio da superficialidade. São Paulo: Annablume, 2010.

HÖFFE, Otfried. Immanuel Kant. São Paulo: Martins Fontes, 2005.

HONNETH, Axel. Luta por reconhecimento: a gramática moral dos conflitos sociais. São Paulo: Ed. $34,2003$.

La sociedad del desprecio. Madrid: Trotta, 2011.

KANT, Immanuel. Fundamentação da metafísica dos costumes. Lisboa: Ed. 70, 2011.

NAPOLI, Philip. Automated media: an institutional theory perspective on algorithm media production and consumption. Communication Theory, [s. 1.], v. 24, n. 3, Aug. 2014. Disponível em: < http://onlinelibrary. wiley.com/doi/10.1111/comt.2014.24.issue-3/issuetoc $>$. Acesso em: 12 out. 2015.

PETIT, Philippe. Liberalismo. In: CANTO-SPERBER, Monique (Org.). Dicionário de ética e filosofia moral. São Leopoldo: Unisinos, 2013.

SPINOZA, Baruch. Ética. Belo Horizonte: Autêntica, 2013.

Princípios de filosofia cartesiana e pensamentos metafísicos. Belo Horizonte: Autêntica, 2015. 
Sites consultados

\section{FACEB00K. Facebook reports second quarter}

2017 results. Site institucional, 2017a. Disponível em: https://s21.q4cdn.com/399680738/files/doc news/2017/FB-Q2'17-Earnings-Release.pdf > . Acesso em: 10 ago. 2017.

. Our mission. Site institucional, 2016b.

Disponível em: < http://newsroom.fb.com/companyinfo/>. Acesso em: 2 ago. 2016.

Princípios do Facebook. Site institucional, 2016c. Disponível em: < https://pt-br.facebook.com/ principles.php >. Acesso em: 6 ago. 2016. 


\begin{tabular}{|c|c|}
\hline $\begin{array}{l}\text { Limits and possibilities for the } \\
\text { formation of recognition in socio- } \\
\text { technical networks }\end{array}$ & $\begin{array}{l}\text { Límites y posibilidades para } \\
\text { la configuración del reconocimiento } \\
\text { en redes socio técnicas }\end{array}$ \\
\hline $\begin{array}{l}\text { Abstract } \\
\text { This study examines how the attributes of socio- } \\
\text { technical networks can contribute to the emergence } \\
\text { of conditions favorable to the emergence of mediatic } \\
\text { forms of recognition and also can jeopardize the } \\
\text { possibility of this inter-subjective experience. } \\
\text { The reflection is based on: the epistemology of } \\
\text { recognition developed by Honneth; the principles } \\
\text { and functionalities of Facebook, assumed as the } \\
\text { reference corpus; and the procedure, adopted and } \\
\text { discussed by Deleuze, of the subtraction of elements } \\
\text { of an object to release its non-dominant meanings. } \\
\text { The relationship between these premises led to the } \\
\text { conceptual shift of the recognition for its admission } \\
\text { into the context of socio-technical networks. } \\
\text { Keywords } \\
\text { Socio-technical networks. Recognition. Sociability. }\end{array}$ & $\begin{array}{l}\text { Resumen } \\
\text { Este estudio discute cómo los atributos de redes } \\
\text { socio técnicas pueden colaborar para la emergencia } \\
\text { de formas mediáticas del reconocimiento y } \\
\text { también pueden colocar en jaque la posibilidad } \\
\text { de esa experiencia intersubjetiva. La reflexión } \\
\text { se articula a partir de las siguientes bases: la } \\
\text { epistemología del reconocimiento desarrollada pos } \\
\text { Honneth; los principios y las funcionalidades del } \\
\text { Facebook, asumidos como corpus de referencia; y } \\
\text { el procedimiento adoptado y discutido por Deleuze, } \\
\text { de substracción de elementos de un objeto para la } \\
\text { liberación de sus sentidos no dominantes. La relación } \\
\text { entre esas bases llevó al dislocamiento conceptual del } \\
\text { reconocimiento, para su admisión en el contexto de } \\
\text { redes socio técnicas. } \\
\text { Palabras clave }\end{array}$ \\
\hline
\end{tabular}




\section{Expediente}

A revista E-Compós é a publicação científica em formato eletrônico da Associação Nacional dos Programas de Pós-Graduação em Comunicação (Compós). Lançada em 2004, tem como principal finalidade difundir a produção acadêmica de pesquisadores da área de Comunicação, inseridos em instituições do Brasil e do exterior.

\section{E-COMPÓS I www.e-compos.org.br I E-ISSN 1808-2599}

Revista da Associação Nacional dos Programas de Pós-Graduação em Comunicação. Brasília, v.20, n.2, maio/ago. 2017. A identificação das edições, a partir de 2008, passa a ser volume anual com três números. Indexada por Latindex I www.latindex.unam.mx

\section{CONSELHO EDITORIAL}

Alda Cristina Silva da Costa, Universidade Federal do Pará, Brasil Alfredo Luiz Paes de Oliveira Suppia, Universidade Estadual de Campinas, Brasil Álvaro Larangeira, Universidade Tuiuti do Paraná, Brasil Ana Carolina D. Escosteguy, Pontifícia Universidade Católica do Rio Grande do Sul, Brasil Ana Regina Barros Rego Leal, Universidade Federal do Piauí, Brasil Ana Carolina Rocha Pessôa Temer, Universidade Federal de Goiás, Brasil Andrea França, Pontifícia Universidade Católica do Rio de Janeiro, Brasil André Luiz Martins Lemos, Universidade Federal da Bahia, Brasil Angela Cristina Salgueiro Marques, Faculdade Cásper Líbero, Brasil Ângela Freire Prysthon, Universidade Federal de Pernambuco, Brasil Antonio Carlos Hohlfeldt, Pontifícia Universidade Católica do Rio Grande do Sul, Brasil Arthur Ituassu, Pontifícia Universidade Católica do Rio de Janeiro, Brasil Bruno Campanella, Universidade Federal Fluminense, Brasil Cláudio Novaes Pinto Coelho, Faculdade Cásper Líbero, Brasil Carlos Eduardo Franciscato, Universidade Federal de Sergipe, Brasil Denise Tavares da Silva, Universidade Federal Fluminense, Brasil Eduardo Vicente, Universidade de São Paulo, Brasil Eliza Bachega Casadei, Escola Superior de Propaganda e Marketing - SP, Brasil Elizabeth Nicolau Saad Corrêa, Universidade de São Paulo, Brasil Erick Felinto de Oliveira, Universidade do Estado do Rio de Janeiro, Brasil Erly Vieira Júnior, Universidade Federal do Espírito Santo, Brasil Francisco de Assis, FIAM-FAAM Centro Universitário, Brasil Francisco Elinaldo Teixeira, Universidade Estadual de Campinas, Brasil Frederico de Mello Brandão Tavares, Universidade Federal de Ouro Preto, Brasil Gabriela Reinaldo, Universidade Federal do Ceará, Brasil

Gilson Vieira Monteiro, Universidade Federal do Amazonas, Brasil Gustavo Daudt Fischer, Universidade do Vale do Rio dos Sinos, Brasi Itania Maria Mota Gomes, Universidade Federal da Bahia, Brasil Jiani Adriana Bonin, Universidade do Vale do Rio dos Sinos, Brasil José Afonso da Silva Junior, Universidade Federal de Pernambuco, Brasil José Luiz Aidar Prado, Pontifícia Universidade Católica de São Paulo, Brasi
Juçara Gorski Brittes, Universidade Federal de Ouro Preto, Brasil Juliana Freire Gutmann, Universidade Federal da Bahia, Brasil Laura Loguercio Cánepa, Universidade Anhembi Morumbi, Brasil Letícia Cantarela Matheus, Universidade do Estado do Rio de Janeiro, Brasil Liziane Soares Guazina, Universidade de Brasilia, Brasil Luíza Mônica Assis da Silva, Universidade Católica de Brasília, Brasil Maria Ataide Malcher, Universidade Federal do Pará, Brasil Maria Elisabete Antonioli, Escola Superior de Propaganda e Marketing - SP, Brasil Maria das Graças Pinto Coelho, Universidade Federal do Rio Grande do Norte, Brasil Marcel Vieira Barreto Silva, Universidade Federal da Paraiba, Brasil Marcia Tondato, Escola Superior de Propaganda e Marketing, Brasil Marli Santos, Universidade Metodista de São Paulo, Brasil Márcio Souza Gonçalves, Universidade do Estado do Rio de Janeiro, Brasil Mauricio Mario Monteiro, Universidade Anhembi Morumbi, Brasil Mauricio Ribeiro da Silva, Universidade Paulista, Brasil Mauro de Souza Ventura, Universidade Estadual Paulista, Brasil Mayka Castellano, Universidade Federal Fluminense, Brasil Micael Maiolino Herschmann, Universidade Federal do Rio de Janeiro, Brasil Mozahir Salomão Bruck, Pontifícia Universidade Católica de Minas Gerais, Brasil Nísia Martins Rosario, Universidade Federal do Rio Grande do Sul, Brasil Potiguara Mendes Silveira Jr, Universidade Federal de Juiz de Fora, Brasil Rafael Grohmann, FIAM-FAAM - Centro Universitário, Brasil Raquel Ritter Longhi, Universidade Federal de Santa Catarina, Brasil Regiane Regina Ribeiro, Universidade Federal do Paraná, Brasil Roberto Elísio dos Santos, Universidade Municipal de São Caetano do Sul, Brasil Rodolfo Rorato Londero, Universidade Estadual de Londrina, Brasil Sérgio Luiz Gadini, Universidade Estadual de Ponta Grossa, Brasil Simone Maria Andrade Pereira de Sá, Universidade Federal Fluminense, Brasil Simone Maria Rocha, Universidade Federal de Minas Gerais, Brasil Suzana Reck Miranda, Universidade Federal de São Carlos, Brasil Tarcyanie Cajueiro Santos, Universidade de Sorocaba, Brasil Tatiana Oliveira Siciliano, Pontifícia Universidade Católica do Rio de Janeiro, Brasil Veneza Mayora Ronsini, Universidade Federal de Santa Maria, Brasil

\section{CONSELHO CIENTÍFICO}

Cristiane Freitas Guttreind, Pontifícia Universidade Católica do Rio Grande do Sul, Brasil | Eduardo Antônio de Jesus, Universidade Federal de Minhas Gerais, Brasil | Eduardo Morettin, Universidade de São Paulo, Brasil I Irene de Araújo Machado, Universidade de São Paulo, Brasil I Miriam de Souza Rossini, Universidade Federal do Rio Grande do Sul, Brasil

\section{COMISSÃO EDITORIAL}

Eduardo Antonio de Jesus, Universidade Federal de Minas Gerais, Brasil I Igor Pinto Sacramento, Universidade Federal do Rio de Janeiro, Brasil I Kelly Cristina de Souza Prudencio, Universidade Federal do Paraná, Brasil I Osmar Gonçalves dos Reis Filho, Universidade Federal do Ceará, Brasil

\section{CONSULTORES AD HOC}

Cesar Augusto Baio Santos, Universidade Federal do Ceará, Brasil I Lilian França Universidade Federal de Sergipe, Brasil I Maria Aparecida Baccega, Escola Superior de Propaganda e Marketing, Brasil I Márcia Benetti, Universidade Federal do Rio Grande do Sul, Brasil I Miguel Serpa Pereira, Pontifícia Universidade Católica do Rio de Janeiro, Brasil | Renato Essenfelder, Escola Superior de Propaganda e Marketing, Brasil

\section{EQUIPE TÉCNICA}

ASSISTENTE EDITORIAL Márcio Zanetti Negrini | REVISÃO DE TEXTOS Melina Santos | EDITORAÇÃO ELETRÔNICA Roka Estúdio I IMAGEM DE CAPA Silas de Paula

COMPÓS I www.compos.org.br

Associação Nacional dos Programas de Pós-Graduação em Comunicação

Presidente

Marco Roxo

Programa de Pós-Graduação em Comunicação - UFF marcos-roxo@uol.com.br

Vice-Presidente Isaltina Gomes Programa de Pós-Graduação em Comunicação - UFPE isaltina@gmail.com

Secretária-Geral

Gisela Castro

Programa de Pós-Graduação em Comunicação e Práticas de Consumo - ESPM castro.gisela@gmail.com

CONTATO I revistaecompos@gmail.com 